\title{
GRÄNSEN SOM MUSEAL STRUKTUR
}

\author{
Bo Lönnqvist
}

Konung Christian IV utsände åren 1605-1606 expeditioner till Grönland, för att bävda rätten över de dansk-norska besittningarna gentemot engelsmännen. Expeditionerna leddes av engelsmannen James Hall som berättar att man vid mötet med eskimåerna på Västgrönland förvärvade deras spjut och vapen $i$ utbyte mot gammal järnsöm, synålar och andra obetydligheter. Intressant är emellertid, att man också tog till fänga eskimåer och deras kajaker.

Sammanlagt nio individer fördes levande till Köpenhamn, där de både studerades av kanslern och historieskrivaren Arild Huitfeldt och visades för publik. De dog snart, av hemlängtan, en av försök att med sin kajak nå Grönland, en under fiske och den sista "av grämelse". Försöket upprepades under Fredrik III:s tid då tre sommarexpeditioner utrustades och man år 1654 hemförde fyra grönländare som blev avmålade i Bergen (enligt Mogens Bencard dock troligen i Köpenhamn), visade i Köpenhamn och studerade av Adam Olearius på Kunstkammer i Gottorp. Målningen som ställdes upp i Fredrik III:s nyinredda Kunstkammer (1650) är den äldsta bevarade av grönlänningar och Olearius kunde skriva sin ingående skildring av deras etnografi på basen av personliga iakttagelser. Avsikten var att sända de tre kvinnorna tillbaka när de lärt sig språket och den kristna religionen (mannen hade dött), men det gick inte några flere skepp i kung Fredriks tid (Dam-Mikkelsen \& Lundbaek 1980, s.15).

Vi har här ett tidigt och talande exempel på museisamlingen som "kategoriskt imperativ", befästare av en världsordning genom klassificering och placering av ting i bestämda hus, i bestämda rum: naturalier, konstsaker, Gewehr, schilderier, mate-

Med genealogi avses i forreliggande text inte foreträdesvis en historisk släktskap, utan - i kulturantropologisk mening - ett självgenererande mönster av kulturella repertoarer som kommer till synes $i$ de betydelser som ges tingen och det kulturella arrangemang som de placeras in i. Museet kan salunda ses som en amöba som om och om igen fortplantar sig själv: genom den mentalitet dess sammanlagda tingmassa, klassificeringen och arrangemanget av denna massa, kunskapen kring den och avgränsningen av densamma uttrycker. 
BO LÖNNQVIST

100 matik, ostindiskt, medaljer, modeller. Så fördelas tingen i det första inventariet över Kunstkammeret i Köpenhamn.

Men försöken att också pressa in människan - eller åtminstone en människoliknande varelse, eskimån - i detta misslyckas. Det är kanske därför man följande gång avmålar eskimåerna (redan i Bergen?), i en aning om att de kanske inte kommer att överleva. Det går inte att förvandla människan till ett ting. Däremot kan tingen bli människa - och det är museets högsta ambition att igångsätta denna förvandlingsprocess.

Museum Europa-utställningen har lanserat de siamesiska tvillingarna som sitt emblem och över museet som koncept ligger ett Janus-ansikte. I den klassificerande gränsen nair museet sin samlande funktion, genom gränsen skapas museets innehall. Samtidigt fär tingen, när de rycks ur sin kontext, en splittrande funktion, nämligen i forhällande till allt det levande, också det mänskliga. Så kan gränsen som museal struktur mera ses som en spegel av mänskliga intentioner och mänskligt tänkande, än av tingens funktion $i$ sig, trots museernas ambition att frambäva den senare. Flera bärande kategorier $\mathrm{i}$ vår kultur och vårt västerländska tänkande - såsom kontinuitet, autenticitet, stabilitet - manifesteras, ja skapas, på ett ypperligt sätt just av museet.

Det är min avsikt att i föreliggande text framhäva museets roll som skapare av och som symbol för kulturell symmetri. Samtidigt kan vi genom tingen studera gränserna för de mänskliga föreställningarna; det gäller inte enbart vad som förblivit utanför museet, utan också vilken sida, dimension och betydelse av tingen man egentligen visar upp i en utställning. För överskådlighetens skull tillgripes här också en gränsdragning, nämligen i vetenskapliga kategorier. Genomgående studeras också överskridandet av gränsen, transgressionen, och slutligen - leken med gränsen den som slutade så olyckligt för eskimåerna.

\section{TINGENS NATURLIGA OCH ONATURLIGA GRÄNSER}

Kunstkammer-principen åtskilde inte de mänskliga skapelserna från naturens underverk. Gränsen mellan natur och kultur är på Kunstkammerets tid flytande och det naturliga bereds rum också i museet - det är den kuriösa blicken - medan den normala världen stannar utanför museet, i åskådarens roll.

Det är ju först under 1800-talet som en uppdelning i kulturhistoriska museer och naturhistoriska museer sker, varvid den västerländska civilisationen făr sin plats inom kulturen, de utomeuropeiska, exotiska, s.k.primitiva folken däremot ofta på de naturhistoriska museerna. Evolutionstanken, upplysningstidens rationalism och industrialismen profilerade denna tingens uppdelning i progressivt och stillastående. Som naturligt betraktades både hög konst och civilisation, det som visade på lång utveckling och hög ålder. Som onaturligt, i betydelsen utanför kulturen, visades naturfolkens liv, detta som inte gick att fästa vid skriften, tidsaxeln eller framstegsoptimismen. Ett intressant exempel på detta innanför/utanför utgör det av Peter den store 1714 grundade Kunstkamera i Sankt Petersburg (i dag Muzej Antropologij $i$ Etnografij) vars ändamål var att framvisa "alla världens folkslag" - på samma sätt som Tsar Peters ambitioner beträffande själva staden Petersburg var att göra den till en multietnisk metropol, utan någon 
specifikt rysk kultur. När efter revolutionen det andra etnografiska museet grundas i staden, kallas detta uttryckligen för De ryska folkens museum, i enlighet med Lenins Sovjetkultur.

En intressant paradox råder däri att de etnografiska samlingarna, det till naturen klassificerade, i dag ofta ger oss en betydligt bredare kontext kring föremålen, deras ekologiska sammanhang, än vad de kulturhistoriska på konnässörsbasis utvalda föremålskategorierna kan förmedla. Vissa moderna museer, som t.ex. Universitetets antropologiska museum i Philadelphia, åtskiljer inte natur och kultur, utan presenterar folkslagen $\mathrm{i}$ en total kontext. I de etnografiska exposéerna är det bärande temat människans förhållande till naturen, i de kulturhistoriska människans förhållande till skriften.

En annan gränsdragning, som förefaller att ha kulminerat under 1900-talet, markerar uppdelningen i kön - manligt/kvinnligt - och könlöshet. Naturfolken saknade kläder eller hade obestämbara skynken, tatueringar, fjäderprydnader, smycken och andra dekorationer, utan europeisk könsmarkering. Också de rituella dräkterna höljer och döljer, även den liturgiska skruden är könlös: mässkåpan eller mässhaken, "mäss-särk" talar man om ännu i slutet av 1600-talet. Också de dräkter och klädesplagg som fick sin plats i 1500- och 1600-talens Kunstkammer, typ Livrustkammaren på Stockholms slott, bevarades för antingen sin funktion av trofé eller kuriositet, de manifesterade legenden, historien, biografin, eller bevarades som undergörande reliker (typ: drottning Margaretas kjortel i Uppsala domkyrka, från början av 1400-talet, till 1659 i Roskilde domkyrka; Sturekläderna 1567; Gustav II Adolfs skjorta från Lützen 1632; Karl X Gustavs kröningsdräkter 1654).
Det är med modet, framförallt under renässansen, dräkten blir könsmarkerande och museernas dräktsamlingar följer efterhand (slutet av 1700-talet) allt noggrannare modejournalerna både köns- och tidsmässigt. Herrdräkt/Damdräkt, Mansdräkt/Kvinnodräkt blir fasta kategorier i utställning och katalog. Transvestiters och andra till könet ambivalenta gruppers klädsel står utanför gränsen till det naturliga jämför t.ex. Drottning Christinas s.k. resdräkt på målningen av Wolfgang Heimbach 1660 (Christina 1966, Bencard 1980). Också barnens klädsel, före det könsmarkerande barnmodet i slutet av 1700-talet, lyser med sin frånvaro. Teatermuseerna visar dräkterna främst i deras rollfunktion, utpräglat historiskt, manligt och kvinnligt. August Strindbergs ambition att göra kostymen på scenen till en del av ordet och budskapet i dramat, har förblivit unik. Ryttmästarens tvångströja i Fadren är, som litteraturvetaren Hans-Göran Ekman visat i sin briljanta studie "Klädernas magi", ett plagg som skriker ut könens kamp, kvinnans styrka som magnetisör och fångvakt, en kombination av hypnos och klädesplagg (Ekman 1991). Strindbergs klädfilosofi genomgår en utveckling som kan fångas i ordräckan: fördärv, förställning, fängenskap, forförelse, forändring, fornedring, och till slut forsoning. De flesta av dessa mentala kategorier faller likväl utanför gränsen för det naturliga, de är också könlösa. Museerna har aldrig ägt dem.

När så folkdräkterna, allmogens dräktskick, under 1800-talet placeras in på museernas etnografiska avdelningar, fäster man stor vikt vid brud- och brudgumsdräkten. Det är bröllopet, den äktenskapliga lyckan, familjen, dopet, begravningen, välsignad av 
102 lång kyrklig tradition och omhuldad av 1800-talets borgerliga ideologi, som blir ett centralt och estetiskt tilltalande tema i den etnografiska dräktutställningen. "Livets högtider" är en stabil kategori i etnografiskt tänkande liksom även $\mathrm{i}$ det sociala livets hierarki. Industrialismens yrkesuniformer under 1900-talet har ytterligare förstärkt könsgränsen som museal kategori.

En tredje gräns, som skall analyseras här under temat naturligt-onaturligt, gäller nuet, det förgångna och framtiden - till tidsaspekten kommer jag senare. Här gäller det verklighetsuppfattningen, källkriterier på det autentiska tinget. Tingets klassificering sker i nuet. Det är nuet som ger tinget dess gränser. Sedan renässansen har "det äldsta" givits hög prioritet, termen antiquitas är synonym med auctoritas, på samma sätt som gravitas är synonymt med majestas (Le Goff 1992, s.29). Museernas uppdelning i förhistoria, historia och nutid är, i förening med framstegstanken, inte bara en kronologi, utan framförallt en värdeskala som också präglat hela den vetenskapliga metodiken: komparationen $\mathrm{i}$ etnografi, konst- och kulturhistoria. Den i många fall tidlösa folkliga kulturen i Europa, som vore förtjänt av en strukturoch mönsteranalys, har pressats upp på tidslinjen: arbetsredskap har blivit museivärdiga för att de har typologiska motsvarigheter i förhistoriska fynd. Odaterade föremål inger bekymmer och väcker misstanke om sentida kopior eller förfalskningar. Gränsen för det äkta och det oäkta är en variant av natur-onatur. Men också onaturen är ju kultur i betydelsen mänsklig skapelse: alla chimärer, myter, kollage, attrapper, fetischer, kulisser, kopior, höljen och fantasier av olika slag, vidgar föreställningsvärlden utöver det konkreta nuet och gör en enhet av nu, förr och framtid. Det är denna enhet museet gång på gång försöker sönderdela. Vi har inget museum som skulle visa modeller av de mänskliga föreställningarna, för varje museum är i sig ett autentiskt, konkretiserat prov på mänskligt tänkande. Jacques Le Goff påpekar i sin studie "History and Memory" om bl.a. moderniseringen, huru den antika andan förknippades med hjältar, mästerverk, storverk, medan det moderna också står för det alldagliga, massiva, diffusa, mystiska, kontemplativa.

I museivärlden innebär det moderna dock en konflikt, en ödeläggelse som legitimerar samlandets och museernas existens. Tradition och modernisering är begrepp som dominerar när det gäller de etnografiska museernas exposéer över folk på jägar- och samlarstadiet, de "primitiva" i motsats till de "utvecklade". På detta sätt inordnas de rationellt $\mathrm{i}$ Museum Europa och kolonialiseras i tid och rum, ekonomiskt, politiskt, kulturellt, socialt, mentalt. Den modernitet som innebär en attackering av gränser - av natur/onatur, kön/könsbyte/könlöshet, tid/tidlöshet - ett äventyr i marginalitet, en opposition mot en konformitet med normen, en förnekelse och en förstörelse, har inte $\mathrm{i}$ högre grad kunnat upptas som museal kategori. Det är ett frågande och reflekterande, kritiskt koncept (jfr Le Goff 1992, s. 37, 41 etc.).

\section{TINGENS ETNOGRAFISKA GRÄNSER}

På utställningen "Sidenvägen", arrangerad på Konstindustrimuseet i Helsingfors 1985, presenterades även tvenne schamandräkter från Sibirien. Dräkterna var upphängda med den öppna kaftanen vänd mot åskådaren, så som man presenterar historiska dräkter. Därmed gick dräktens 
sentliga kvalitet och innebörd förlorad, imligen det dekorerade ryggpartiet, rikt behängt med djurfigurer, dockor, ormar och andra andesymboler, gåvor av människor schamanen botat, ävensom bjällror och andra ting avsedda att skrämma bort onda andar. Att den sibiriska schamandräkten, som hör till de märkligaste skapelserna inom dräktkulturen, måste kompletteras av trumman framgick inte heller. Det är ju uttryckligen bland de stammar där trumman saknar ornering som dräktens ryggparti fått överta rollen av kosmos, medan t.ex. bland samerna den med tecken försedda trumman har kosmosfunktion, varför någon speciell dräkt inte behövs (Lönnqvist 1985 b).

I museet får tingen alltså en klar etnografisk gräns, i betydelsen given deskription, visuellt gestaltad. De mest dominanta gränserna är tids-och rumsavgränsningarna: föremålet måste dateras, hänföras till en viss kultur- eller stilperiod, till ett visst geografiskt och etnografiskt rum. Det måste vidare få ett namn, inordnas $\mathrm{i}$ en museal nomenklatur, som överensstämmer med en allmän kulturklassificering - men som inte beaktar tingen som en levande process med många skepnader. I sitt arbete "Allgemeine Culturgeschichte der Menschheit" (Dresden 1843) - en föregångare till Edward B.Tylors "Primitive Culture" (1871) - avgränsade Gustav E. Klemm kulturen på ett sätt som blivit grundläggande för tanken i det europeiska museet, även om det hade äldre förebilder. Det är evolutionistiskt, bygger på ett tänkande i stadier och framsteg. Kulturhisto-riens innehåll är: fysisk antropologi, dräkt, ornament, jaktredskap, transportredskap, bostad, hushållsredskap, behållare, verktyg., föremål i anslutning till döden, det offentliga livets insignier (kronor, fredspi103 por), krigets föremål, religiösa objekt och till slut "kulturen", d.v.s. musikinstrument, dekorativa ornament, kartor, teckningar, illustrationer till det skrivna ordet, poetiska och oratoriska produkter från olika nationer (jfr Kroeber \& Kluckhohn 1952). Detta är ett kulturinventarium som motsvarar civilisationsidealet i sin borgerliga, tyska form: "Bildung". Det är den finala fasen för kulturen, en stelnad, icke produktiv kultur som byggs upp inom det nationella museet. Det är i enlighet med denna logik man bland de primitiva folken tagit tillvara vapen, musikinstrument, kultföremål och dräkter.

Vissa "vilda" föremålsgrupper låter sig svårligen fångas i detta paradigm. På Germanisches Nationalmuseum i Nürnberg var dockorna ännu på 1880-talet utställda i samlingen av dräkter och smycken. Leksakerna som en särskild föremålsgrupp skildes första gången ut på 1890 -talet och erhöll ett eget rum. Det var dockor, dockskåp, tennfigurer och sällskapsspel. Sedermera utnyttjades museets leksaker bl.a. för julutställningarna. Det är därför inte ägnat att förvåna, att 1800talets borgerliga syn på leksaken som ett av de vuxna gjort ting med önskvärda egenskaper, vilket ställes framför barnet att leka med, medan de vuxna ser på i hägnet av julträdet eller genom barnkammarens nyckelhål, blir den dominanta också på museerna. Det lekande barnet förblir lika osynligt som förut (jfr Lönnqvist 1992, s. 56). Leksaken som kulturinventarium har emellertid styrt också hela den vetenskapliga aktiviteten kring ting, rum och barn: böcker om lek och leksaker, leksaksmuseerna och de olika synerna på ting och barn: 
104 I den kulturbistoriska samlarsynen, som tagit fasta på leksakernas historiska och geografiska prägel, har tingens konstans genom sekler framhävts. Leksaken har fått fungera som ett kunskapsobjekt om kulturella varianser, hantverkskunnighet, sociala och estetiska representationsbehov.

I den etnografiska synen har tingens ålder och en formkontinuitet, tradition och imitation samt naturmiljöns betydelse (hemgjorda leksaker) framhävts. Detta mot bakgrunden av en presumerad lekinstinkt, som ju förutsätts redan av Immanuel Kant. Leksakernas allmänvärldsliga karaktär poängteras i de etnografiska studierna.

I problematiseringen av leksaksbegreppet utgående från funktionalistiska, strukturalistiska eller psykologiskt-pedagogiska synsätt, har leksaken som en ren spegel av kulturen, eller som ett socialisationsmedel behandlats. Mot sådana, något schematiska synsätt, vände sig i tiden både Yrjö Hirn och Johan Huizinga, den förre framhållande lekens karaktär av både allvarlighet och overklighet, den senare poängterande lekens förmåga att skapa egen tid och eget rum och förverkliga en tingens högre ordning. Det är först i 1970-talets psykologiska studier över lekstrukturen som en helt specifik form av abstraktion, man kommit in på leksakernas symbolbärande roll i barnens egen värld (den "innersubjektiva" processen) och den process där verkligheten både upphävs och fördjupas genom variation (genom imagination). (Lönnquist 1992, s. 371).

Vi har härmed exemplifierat hur tingens etnografiska gränser blir både ideologiska, kronologiska och genealogiska gränser, genealogiska i bemärkelsen självgenererande kulturell klassificering, som lämnar det lekande barnet, den levande vilden, utan- för museivitrinen.

Tingens etnografiska gränser, definierade av museet, upptar det livlösa föremålet i kulturens sfär och ger tinget dess betydelse enligt tema, geografi, kronologi och estetik. Museet blir sålunda också, för att igen hänvisa till Le Goff, "en fabrik för historia", en tendens som framträder utpräglat efter Franska revolutionen med arkeologen Alexandre Lenoir och år 1796 med Museet för franska monument, med Jules Michelet och år 1833 då LouisPhilippe beslöt om restaurering av Versailles till "Frankrikes ära" (Le Goff 1992, s. 14 f.).

\section{TINGENS KLASSMÄSSIGA OCH ETNISKA GRÄNSER}

En mera dold struktur i museets gränsskapande mekanismer än den ovan diskuterade etnografiska, är den klassificering som ger tingen deras sociala värde, ofta i korrespondens med deras ekonomiska försäkringsvärde. Den banala klichén "museerna visar sina skatter" frodas oantastad i vår tid.

Uppdelningen av museerna på naturhistoria och kulturhistoria vid mitten av 1800-talet producerade också de tre skilda vetenskapsgrenarna Kulturgeschichte, Volkskunde och Völkerkunde. Först i vår tid håller den konstgjorda gränsen mellan "hemlandsetnologi" och utomeuropeisk kulturantropologi på att överbyggas. För t.ex. den nordiska etnologin och även de etnografiska samlingarnas uppdelning i eget och främmande har den obefintliga kunskapen om kulturantropologins teorier varit katastrofal, den karakteristiska metoden - fältarbetet - är ju densamma, även om metoden att "ta den andres roll" äger högsta prioritet inom antropologin. 
Skillnaden mellan folkkultur och högreståndskultur har kanske fătt sitt mest markanta uttryck i dräktsamlingarna. Begreppet folkdräkt är ju i många avseenden en museal illusion, ett uttryck för den romantiska nationella ideologin i ståndssamhället (Lönnquist 1985). Dikotomin folkdräkt-modedräkt har emellertid genealogiska rötter bakåt till 1700- och 1600-talen. Det är klädselns klassmarkerande funktion som bör understrykas. Men denna aspekt gick förlorad då folkdräkten gjordes till en symbol för folkliv, lokal kultur, hemslöjd och estetiska ambitioner, tillfredsställande ro-mantikens borgerliga smak. Likaså poängterades folkdräktens arkaiska drag, vilket fick ett klassförsonande hölje då dräkten genomgående ställdes ut mot det snabbt växlande modet (jfr Lönnqvist 1991).

En annan kultur, vars sociala och etniska aspekter skulle öppna spännande dimensioner på "tingen som kulturelle udsagn" är maten, - om den över huvud vore utställd. Matvanor, bordsskick, bordsdukningar, menyer, kokkonst och etikett hör ju till de intimaste kulturella indikatorerna, där andra gränser i mänskligt liv uttrycks än de rent näringsmässiga och tekniska. Bortser man från det dukade bordet som kulturhistoria framträder ett mönster av rollspel, makt, etniska gränser och betydelsebärande kategorier kring kroppen och samfundet och de kulturella barriärer som verkar utan skrivet språk (jfr Mennell 1991).

Mitt sista exempel gäller skolkulturen. Härmed avses inte det officiella ramverk skolmuseerna som statens tjänare dokumenterat. Med skolkultur avses, i analogi med barnkultur, det osynliga mönster av liv skolan som kulturellt samfund skapar. Det är allt det som eleverna, "det främ- mande folket i klassrummet", spontant 105 producerar i ett spänningsfält av revirtänkande, protester, ett bestämt parodiskt språk (med bl.a. palindrom), nonverbalt kroppsspråk, hierarkier och ritualer med starkt betydelsebärande funktion. Det är en flyktighetens kultur och en ögonblickets strategi för överlevnad. Ett antropologiskt synsätt på denna kultur erbjuder unika inblickar i hur kultur kommer till och formas, i en förtätning av människor. Det visar också på andra föreställningar om kunskap än skolans ooch samhällets konventionella syn. Slutligen erbjuder det antropologiska fältarbetet i klassrum och skola en möjlighet att få fram principer i mänskligt kulturellt arrangemang: ordningens princip och dess motsats, det formalistiska och det fria, samt framförallt gränsöverskridandet som mänsklig kulturell resurs: pojkstreck och initiationsriter (jfr Lönnquist 1992 b).

\section{SAMMANFATTNING - PREFERENS FÖR KAOS?}

Det måste väl accepteras, att det europeiska museet som en spegel av västerländskt tänkande, i hög grad är bundet till föreställningar om den lineära tiden, om rummet och om språket. Därmed har också begrepp som kontinuitet och förändring, det historiska perspektivet, herraväldet över rummet, blivit avgörande för hela museiinstitutionen, ja man kan säga att den utgått ur dessa "ursymboler" (för att tala med Spengler). Jag ser gränsen som ändå mera primär, emedan den ju är förutsättningen för tid och rum. Det är ju symptomatiskt att museernas magasin oftast är det mest givande för vetenskaplig forskning - det är kaos! Ovan har gränsen 
106 som museal struktur lyfts fram i sin dubbla egenskap av inneslutande och uteslutande mekanism. Den inneslutande egenskapen har betytt tingens endimensionalitet. Det är ett antropocentriskt perspektiv, museet skall visa allt det som finns utanför den europeiska människan med henne själv som centrum och åskådare. Detta perspektiv visar oss tingens maktgränser, t.ex. när det gäller leksaker som uttryck för uppfattningar om barnet. Gränsens andra funktion, nämligen som någonting som lockar människan att överskrida tid, rum, språk och tingens betydelser, är ett betydligt mera krävande musealt koncept, eftersom det rör sig om en process. Människan ställs här utanför tingen. Tingen blir människan.

Transgressionen, leken med gränsen, innebär ju tingens förvandlingar, en ständigt pågående process som t.ex. barnets lek med föremål uttryckligen exemplifierar. Det är också frågan om att fånga tingens symbolvärden, inte som fasta värden, utan som "ringar på vattnet". Detta processuella är, för att igen exemplifiera med klädkulturen, när Strindberg knyter kostymen till könskampen: när kvinnan sätter på mannen ett plagg (en slät ring) fängslar hon honom. Är det ett kvinnoplagg, t.ex. bara en schal, förnedrar hon honom. "Broscher som ödlor och andra orena djur", kan det heta om smycken. Klädesplaggen kan även tolkas som sociala troféer och symboler för antingen fångenskap i en viss social position eller frigörelse från denna. Avklädning och färger kan markera en förändring i moraliskt-religiöst avseende. Påklädning kan göra en människa besatt, det är magi, eller ladda hela scenen med erotik. I Strindbergs "Ett drömspel" är klädselspråket centralt: schalen är barmhärtigheten, kransen både utkorelse och förnedring - en bild av livets bedräglighet - och törnekronan martyriet. Barnplagg kan symbolisera försoning, kvinnoskon blir en barnsko och fetischen - en suvenir (Ekman 1991).

Kräver vi det orimliga av museet när vi om vi - inte accepterar dess begränsningar, om vi inte slår oss till ro med museets roll som officiell sanningsspegel? Riksutställningar i Sverige har i Tom Sandqvists regi och med några svenska och norska konstnärers hjälp producerat utställningen $N u k e$ Collection - kriget som forfor. Här tar man utgångspunkt i språkformer som utvecklats inom kärnvapenindustrin. Det är kriget som förförande tecken och språk och den sexistiska karaktären hos detta språk som lyfts fram. Genom fetischen missilen och dess namn - och fotografiet, visualiseras fenomenets karaktär, som sammanfaller med liknande element i design och marknadsföring av t.ex. exklusivt herrmode - kalsonger - av kända europeiska modeskapare, såsom betecknande för det västerländska mansidealet. Språket i förbund med tingen gör på detta sätt kriget ofarligt, tillochmed attraktivt eller lätt löjligt - genom de potensladdade, raffinerat sexistiska, offentligt osynliga men dock "missilutlösande" klädesplaggen, kalsongerna. Utställningen Nuke Collection är ett exempel på ett gränsöverskridande museikoncept, en studie i modernitet, där utgångspunkten är språkets värld. Likväl är vi bundna till den västerländska skriftkulturen. Också denna utställning avgränsar när den går över gränsen, en utställning blir alltid absolut. Likväl ger experiment av detta slag uppfordrande inblickar i kulturellt tänkande och visar framförallt på vilken bärande kategori gränsen och 
transgressionen är i kulturen.

Tingen är inte oantastbara, inte ens på museum. När Sovjetväldet föll sönder och samman började småningom uppgifter sippra ut också om mausoleet på Röda torget i Moskva. Kommunismens och det socialistiska samhällets sönderfall har ackompanjerats av konstaterandet att också Lenins kropp håller på att förvittra, all raffinerad balsameringskonst till trots! Ibland är verkligheten underbarare än dikten. Människan på museum är alltid ett gäckande koncept.

\section{SUMMARY}

\section{The Borderline as a Museological Structure}

Bo Lönnqvist discusses the cultural borderlines which are applied in museum classifications and presentations. Museums tend to establish and confirm a world order through the distinctions they make in ordering the collected objects and arranging them in specific buildings, rooms and showcases. Thus the structuring can be regarded as a mirror of human intentions and thinking. The paper elucidates some of the cultural symmetries created by the museum.

First the dichotomy of nature/non-nature is discussed. The Kunstkammer did not distinguish between wonders of nature and of human creativity, to the curious eye such a distinction is unimportant. In the 19th centrury the differentiation between museums of natural and cultural history is made. Western civilization becomes the subject of the museum of cultural history, 'primitive peoples' belong to the museum of natural history. Also gender as well as time regarded as aspects of culture become distinctions of importance.

Then the ethnographic boundaries of objects are looked at. Objects are defined as belonging to specific moments in time and places in space and subordinated the idea of evolution. Many other aspects are only partially understood or left aside - e g the toys and their cultural significance. The ethnographic borderlines defined by the museum accept the lifeless objects in the cultural sphere and give them a significance according to theme, geography, chronology and aesthetics. The museum becomes, as Le Goff has put it, 'a producer of history'.

The third part of the paper treats the class and ethnic boundaries of objects. Costumes and school culture are focussed on. The distinctions based on social classification and economy are often hidden. However the distinction between upper class and folk culture is normally paid attention to - especially in the presentation of costumes. The dichotomy folk costume/fashion should be stressed as class indicator, but the aspect was lost when folk costumes were used as the symbol of an imaginary folk lifestyle to satisfy middleclass taste. The possibility to use food, eating habits and the laying of tables for meals in different settings is pointed at as they express patterns of power, ethnic identity and meanings concerning the human body and society. They are cultural barriers operating without verbal codes. The same potential can be found in the study of the class-room society. Bo Lönnqvist is advocating the use of anthropological field-work methods, which offers unique opportunities to study how a culture is created, formed and changed. A dynamic approach which would immensely enrich and vitalize the interpretation of cultural processes which all the time include the transgressing of cultural borderlines. In many exhibitions those are perceived and presented as eternal instead of temporary.

$\mathrm{He}$ concludes that the European museum as a mirror of Western thinking is linked to ideas of linear time, of space and of language. Hence concepts like continuity and change, historical perspective, control of space, have become decisive for our idea of the museum. 


\section{LITTERATUR}

Bencard, Mogens 1980: Den stumme maler Wolfgang Heimbach. Særudstilling julen 1980påsken 1981. Rosenborg.

Christina Drottning av Sverige - en europeisk kulturpersonlighet. Nationalmuseum, Stockholm 1966. Nationalmusei utställningskatalog 305.

Dam-Mikkelsen, Bente \& Lundbaek, Torben 1980: Etnografiske genstande i Det kongelige danske Kunstkammer 1650-1800. Nationalmuseet Köbenhavn .

Ekman, Hans-Göran 1991: Klädernas Magi. En Strindbergsstudie. Gidlunds Bokförlag, Värnamo.Anmäld av Bo Lönnqvist i Hufvudstadsbladet, Helsingfors 29.11.1992

Kroeber, A.L. and Kluckhohn, Clyde 1952: CULTURE A critical review of concepts and definitions. Papers of the Peabody Museum of American Archaeology and Ethnology, Harvard University Vol.XLVII, No.1. Cambridge, Mass. U.S.A.

Le Goff, Jacques 1992: History and Memory. Columbia University Press.

Lönnqvist, Bo 1985: Volkstracht als museale Illusion. Ein Projektbericht. Mode Tracht Regionale Identität. Historische Kleidungsforschung heute. Referate des internationalen Symposions im Museumsdorf Cloppenburg, Niedersächsisches Freilichtsmuseum, herausgegeben von Helmut Ottenjann.

Lönnqvist, Bo 1985 b: Schamandräkter i Sibirien. Former och funktioner, ålder och ursprung. Finskt Museum 1985. Finska Fornminnesföreningen, Helsingfors.

Lönnqvist, Bo 1991: Folkkulturens skepnader. Till folkdräktens genealogi. Schildts Förlag, Helsingfors.

Lönnqvist, Bo 1992: Ting, rum och barn. Historisk-antropologiska studier i kulturella gränser och gränsöverskridande. Kansatieteellinen arkisto 38. Finska Fornminnesföreningen, Helsingfors.
Lönnqvist, Bo 1992 b: Det höga och det låga i kulturen. Antropologiska studier i den urbana världen. Elever i klass II A i Brändö Gymnasium, Helsingfors. - LABORATORIUM för folk och kultur Bulletin 1/1992. Brages sektion för folklivsforskning, Helsingfors.

Mennell, Stephen 1991: On the Civilizing of Appetite. The Body, Social Process and Cultural Theory, ed.by M.Featherstone, M.Hepworth, B.S.Turner. Sage Publications, London.

Stanjukovic, T.V. 1978: Etnograficeskaja Nauka i Muzei. Akademija Nauk SSSR. Leningrad.

Bo Lönnqvist har en lång bana bakom sig som universitetslärare och forskare $i$ etnologi. Nyligen har han utgivit 'Ting, rum och barn. Historisk-antropologiska studier $i$ kulturella gränser och gränsöverskridande' (1992). Han leder nu projektet 'Svenskheten $i$ Finland' vid Finlands Akademi.

Adr: Föreningen Brage, Kaserngatan 28, SF-00130 Helsingfors. FAX +3580636513. 